\title{
INVESTIGAR COM AS CRIANÇAS: DAS NARRATIVAS À CONSTRUÇÃO DE CONHECIMENTO SOBRE SI E SOBRE O OUTRO
}

TERESA SARMENTO

https://orcid.org/0000-0002-2371-399X

Universidade do Minho

MILENA OLIVEIRA

https://orcid.org/0000-0001-7331-5175

Universidade Federal Rural do Semi-Árido

RESUMO A imagem ocidental da criança contemporânea que subscrevemos - ativa, competente, com agência própria - desafia as concepções e as práticas das educadoras de infância. 0 propósito que nos move na escrita deste texto ${ }^{1}$ reside na análise de modos de participação das crianças em contextos educativos e na relevância das narrativas (auto)biográficas na organização do trabalho pedagógico. Neste artigo, procuraremos desconstruir como atender às narrativas (auto) biográficas que os meninos e as meninas constantemente produzem pode permitir um processo educativo bem sustentado e significativo no desenvolvimento pessoal de cada uma e no desenvolvimento profissional do educador. A base de análise aqui mobilizada foi constituída pela observação de um grupo de crianças entre três e cinco anos de idade que frequentam um jardim de infância de uma localidade da região norte de Portugal. De forma mais específica, procuraremos discutir a relevância das investigações com as crianças em três cenários: 1) partindo das narrativas das crianças como reconhecimento do direito a serem ouvidas e respeitadas em seus interesses, necessidades e modos próprios de participação; 2) como princípio básico na planificação e organização da ação educativa em uma perspectiva de trabalho com projetos; 3 ) como elemento essencial para (re)pensar a formação de professores partindo da ideia de que a investigação no cotidiano das práticas permite o desenvolvimento da capacidade investigativa e reflexiva de crianças e adultos.

Palavras-chave: Narrativas (auto)biográficas. Escuta. Trabalho com projetos. Formação de professores.

1 Este trabalho foi financiado por Fundos Nacionais através da Fundação para a Ciência e a Tecnologia (FCT) no âmbito do projeto do Centro de Investigação em Estudos da Criança da Universidade do Minho (CIEC) com a referência UIDB/00317/2020. 
ABSTRACT INVESTIGATING WITH CHILDREN: FROM NARRATIVES

TO THE CONSTRUCTION OF KNOWLEDGE ABOUT

\section{THEMSELVES AND THE OTHER}

Contemporary western image of child, that we subscribe to, - active, competent, with its own agency - challenges the conceptions and practices of Kindergarten Educators. The goal of this text is to analyze forms of children participation in educational contexts and to know the relevance of (auto) biographical narratives in the organization of pedagogical work. At this paper we will try to deconstruct how to attend (auto) biographical narratives produced by boys and girls constantly produce can allow a well-sustained and significant educational process in the personal development of each one and in the professional development of the educator. We produced an observation and analyzed documentation produced for a young teacher in training of a group of children between 3 and 6 years old who attend a kindergarten in a locality in the northern region of Portugal. We will try to discuss the relevance of research with children in three scenarios: 1) starting from the children's narratives as recognition the right to be heard and respected in their interests, needs and specific ways of participation; 2 ) as a basic principle in the planning and organization of educational action from the perspective of working with projects; 3 ) as essential to think new forms of teacher teaching from the idea that the research in the daily practices allows the development of the investigative and reflective capacity of children and adults.

Keywords: Narratives. Listening. Pedagogical projects. Teacher training.

RESUMEN INVESTIGANDO CON LOS NIÑOS: DE LAS NARRATIVAS A LA CONSTRUCCIÓN DEL CONOCIMIENTO SOBRE SÍ MISMOS Y EL OTRO

La imagen occidental del niño contemporáneo, activa, competente, con su propia agencia, desafia las concepciones y prácticas de los educadores. Nuestro propósito es la análisis de los modos de participación de los niños en contextos educativos y en la relevancia de las narrativas (auto) biográficas en la organización del trabajo pedagógico. En este artículo intentaremos deconstruir cómo atender las narrativas (auto) biográficas que los niños y las niñas producen constantemente pueden permitir un proceso educativo significativo y bien sostenido en el desarrollo personal de cada uno y en el desar- 
rollo profesional del educador. La base de análisis movilizada aquí estuvo constituida por la observación e la documentación pedagógica que há escrito una estudiante para maestra de un grupo de niños entre 3 y 6 años que asisten a un jardín de infantes en una localidad de la región norte de Portugal. Nos interessa discutir la relevancia de las investigaciones con niños en tres escenarios: 1) a partir de las narrativas de los niños como reconocimiento del derecho a ser escuchado y respetado en sus propios intereses, necesidades y formas de participación; 2) como principio básico en la planificación y organización de la acción educativa desde la perspectiva de trabajar con proyectos; 3) como elemento esencial para (re) pensar la formación de docentes a partir de la idea de que la investigación en las prácticas diarias permite el desarrollo de la capacidad investigativa y reflexiva de niños y adultos.

Palabras clave: Narrativas. Escucha. Trabajo por proyectos. Formación de maestros.

\section{Introdução}

A imagem ocidental, acerca da criança contemporânea, que subscrevemos - ativa, competente, com agência própria - desafia as concepções e as práticas das educadoras de infância. O propósito que nos move na escrita deste texto reside na análise de modos de participação das crianças em contextos educativos e na relevância das narrativas (auto)biográficas na organização do trabalho pedagógico. Nos contextos educativos, concretamente em jardinsde-infância², como partir das narrativas das crianças, respeitando assim os seus interesses e os modos próprios de cada criança para a dinamização da ação educativa? Como desenvolver uma escuta atenta e sensivel diante de um grupo de crianças? Como partilhar as decisões com as crianças para, investigando com elas, aceder à construção de conhecimento sobre si - crianças e educadora - e sobre o outro, entendendo este como o seu microcosmos, ou seja, o contexto físico, biológico e social, de

2 Jardins-de-Infância é a designação usada em Portugal para as instituições educativas de crianças dos 3 anos - a idade de entrada na escola do 1o ciclo, o que corresponde às escolas infantis brasileiras. que cada um faz parte? Esses e outros desafios têm provocado as educadoras a (re)pensar o conjunto de saberes necessários ao desenvolvimento da ação educativa que respeite os sujeitos da ação - as crianças e seus responsáveis - com suas culturas e saberes diversos.

Nos últimos anos, as investigações com e não apenas sobre as crianças (PASSEGGI; NASCIMENTO; OLIVEIRA, 2016) têm nos ajudado a compreender as crianças em seus contextos, com suas crenças e culturas próprias. Em texto anterior, clarificamos que "as narrativas autobiográficas produzidas no contexto educativo [pelas crianças] podem ser relevantes, ao mesmo tempo ou não, a dois níveis, o pedagógico e o investigativo". (SARMENTO, T., 2018, p. 127). Ou seja, ouvir o que as crianças têm para nos contar pode ser mobilizado para a definição da ação pedagógica a prosseguir com elas ou, noutro sentido, por vezes concomitante, para as conhecer em diferentes sentidos - quem são, como são, como se constroem e desenvolvem enquanto membros de uma comunidade, quais as suas culturas específicas. A 
abordagem que seguimos entende a criança como sujeito biográfico na sua "complexidade dialética de nossa própria humanidade e de nossas múltiplas faces" (PASSEGGI, 2016, p.70), na base da proposta de Ricoeur (1994), quando este sugere que, enquanto sujeitos, nós sofremos e agimos ao mesmo tempo, o tempo todo. Ou seja, ao narrar, a criança, ainda que subordinada a regras sociais, tem sempre margem de iniciativa e decisão para reconstruir a sua realidade, e o faz na sua inteireza, com o seu pensar, o seu sentir e o seu querer, isto é, afirma-se como sujeito biográfico. Neste texto, procuraremos abordar esses dois âmbitos, salientando o cruzamento dos mesmos; ou seja, analisamos como atender às narrativas (auto) biográficas que constantemente as crianças produzem pode permitir um processo educativo bem sustentado e significativo no desenvolvimento pessoal de cada uma das crianças e dos seus educadores.

Mobilizamos de Barbier o conceito de escuta sensivel, entendida como "um escutar-ver" (2002, p.1), em que, enquanto docentes-pesquisadoras apoiadas na empatia com as crianças em jardim-de-infância, procuramos "sentir o universo afetivo, imaginário e cognitivo do outro para poder compreender de dentro suas atitudes, comportamentos e sistema de ideias, de valores de símbolos e de mitos" (ibidem). Assim, num processo de escuta sensivel, defendemos que a ação educativa não é um ato isolado e vertical, centralizado apenas na figura docente, mas, isso sim, é um ato partilhado com as crianças e suas famílias. As suas ideias, seus modos de ser, estar e interagir, porque de ações humanas se trata, intervêm no desenvolvimento profissional do educador, ainda que este possa não ter consciência imediata dessa contribuição.

Com Conceição Moita (2007), afirmamos que, no decorrer da ação docente, o educador vivencia situações que se convertem em pro- cessos parciais de formação, e que "por vezes, estes processos começam por ser reações a circunstâncias provocadoras, ou são desencadeados por crises e situações dissonantes. Não são lineares, mas muitas vezes vividos em vias labirínticas". (MOITA, 2007, p. 137). 0 tempo diário, em jardim-de-infância, é organizado numa sequência que designamos por 'rotina pedagógica', concretizada usualmente numa sequência regular de atividades, de forma a garantir estabilidade e segurança às crianças que assim podem antecipar, no seu dia a dia, o que irá acontecer em cada momento. As circunstâncias acima referidas podem ocorrer em diferentes momentos da rotina pedagógica, pois as narrativas das crianças, suas dúvidas, ideias, anseios, provocam a todo momento o educador a repensar o seu saber e o seu fazer.

Neste texto analisaremos registos de situações vivenciadas com um grupo de crianças entre três e seis anos de idade, de um jardim de infância de uma localidade da região norte de Portugal. 0 grupo é composto por 22 crianças, uma educadora de infância ${ }^{3}$ e uma auxiliar, integrando, no tempo em que foi realizada a observação, uma estagiária de um mestrado profissionalizante para a docência. Ressaltamos que a prática pedagógica da educadora de infância é orientada pelos princípios do Movimento da Escola Moderna portuguesa (MEM) ${ }^{4}$.

Em sintese, neste artigo, o nosso objetivo é discutir a relevância das investigações com as crianças, em três cenários: 1) partindo das narrativas das crianças como reconhecimento do direito a serem ouvidas e respeitadas em

3 Educadora de infância é a designação portuguesa de profissional de educação de crianças de zero a seis anos de idade, referida no Brasil como professora de infantil. Neste texto, pode aparecer uma ou outra designação.

4 O Movimento da Escola Moderna (MEM) é a designação de um movimento associativo de professores e, ao mesmo tempo, do modelo pedagógico em que assentam as práticas desenvolvidas pelos mesmos, numa base socioconstrutivista de construção de conhecimento. 
seus interesses, necessidades e modos próprios de participação; 2) como princípio básico na planificação e organização da ação educativa numa perspectiva de trabalho com projetos; 3) como elemento essencial para (re)pensar a formação de professores partindo da ideia de que a investigação com as crianças, no cotidiano das práticas, permite o desenvolvimento da capacidade investigativa e reflexiva.

\section{A escuta sensivel de narrativas de crianças: modos próprios de participação}

A visão ocidental contemporânea de criança e de infância é múltipla, sendo possivel percorrer uma longa distância entre os que mantêm o olhar sobre a mesma numa perspetiva lockeana, em que a criança é metaforicamente apresentada como uma tábua rasa em que há que inscrever tudo o que ela necessita, até, em contrapartida, um olhar sustentado num conjunto de conhecimentos dos estudos da criança que a tomam como agente de conhecimento, sujeito concreto, real, imbricada com os contextos socioculturais em que vive. A infância é, assim, um conceito heterogêneo, constituindo uma categoria geracional universal, cuja construção é social e historicamente muito diferenciada. Nessa linha, entende-se a infância como realidade social emergente no âmbito de um conjunto de processos sociais e culturais, entre outros. As crianças são sujeitos individuais e singulares, integrantes da categoria geracional infância.

Dahlberg, Moss e Pence propõem que "[...] há muitas crianças e muitas infâncias, cada uma construída por nossos entendimentos da infância e do que as crianças são e devem ser" (2003, p. 63). Numa perspectiva semelhante, Kramer defende “[...] uma visão da criança como cidadã, sujeito criativo, indivíduo social, produtora da cultura e da história, ao mesmo tempo que é produzida na história e na cultura que lhe são contemporâneas" (2002, p. 43); ou seja, conhecer a criança permite-nos aceder ao mundo em que vive "a partir do ponto de vista da infância, pode nos ajudar a aprender com elas" (KRAMER, 2005, p. 91), o que nos obriga a uma monitorização constante das nossas asserções, a uma disposição para pormos em causa as nossas certezas e nos abrirmos a um conhecimento novo, continuamente reconstruivel.

Nesses estudos, destaca-se, além da concepção de criança e de infância como singulares, não homogêneas, a importância do reconhecimento das especificidades infantis, aquilo que, ao lado de toda diversidade que singulariza cada criança, e cada infância, lhes é comum, embora experimentado de modos tão diversos quanto são os contextos de vida que habitam e em que interagem.

Essas proposições corroboram a ideia da criança capaz, competente e produtora de cultura, sendo a ludicidade o principal meio pelo e no qual expressam e vivenciam as suas experiências, em que recriam o real que thes é acessivel e criam novas realidades. Ao enxergarmos a criança como ser humano capaz, no campo educativo, comprometemo-nos a construir interações significativas em vista ao desenvolvimento da sua aprendizagem global. Essas concepções marcam, de modo incisivo, a compreensão acerca das práticas educativas a elas dirigidas, assim como os requisitos postos aos educadores responsáveis e, portanto, à sua formação.

Partindo dessa discussão de criança e infância, entramos no campo dos direitos das crianças como uma etapa inicial de construção dos direitos dos cidadãos. Respeitar o direito à participação das crianças tem se constituído um desafio diário para as práticas pedagógicas dos educadores, por requerer dos mesmos uma escuta sensivel, traduzida por 
[...] escuta enquanto processo ativo de comunicação, consistindo em ouvir, interpretar e construir significados que não se limitam à palavra falada, mas tomam como ponto de partida o facto de crianças e adultos estarem expostos a múltiplas vozes, múltiplas perspetivas nos olhares e pensamentos sobre a aprendizagem, sobre a criança e sobre a profissão e, ainda, múltiplas noções de qualidade em Educação. (COSTA e SARMENTO, T. 2018, p. 75).

Nessa perspetiva, assumindo a agência da criança e reafirmando a pertinência de ouvir as suas vozes, concordamos com Larrosa (2006, p. 184) quando o autor diz que a infância desestabiliza "a segurança de nossos saberes, questiona o poder de nossas práticas e abre um vazio em que se abisma o edificio bem construído de nossas instituições de acolhimento", o que promove o desenvolvimento profissional dos educadores.

Malavasi e Zoccatelli (2019, p. 8) afirmam que:

[...] a ação educativa não é a de transmitir, mas a de escutar; um escutar ativo e participante que coloca o adulto por sua vez, numa situação de contínua aprendizagem e que, ao mesmo tempo, torna-o num atento e pontual observador, em condições para acolher as solicitações e necessidades cognitivas das crianças.

Ou seja, esse processo de escuta, afirmado como base da ação pedagógica por esse conjunto de autores, retomam o espaço que as narrativas - em diferentes tempos, espaços e lugares - ocupam na constituição do humano da criança que narra e do educador que escuta. Nessa mesma linha, Lopes (2016, p. 15) refere que "os professores precisam criar situações cotidianas de ouvir as crianças verdadeiramente, em que elas possam relatar fatos, contar experiências, opinar e falar dos seus sentimentos em relação a essas experiências". Ou seja, oportunizar situações de uma escuta atenta e verdadeira, pois a narrativa da criança aponta indícios dos seus interesses.
Investigar com as crianças no chão da escola: contribuições para a prática educativa e formação do educador

Compreendemos a investigação como um percurso de construção do conhecimento dinâmico e dialógico, bem como um princípio educativo que oportuniza novas formas de conhecer e interpretar a realidade. Na escola, espaço em que as crianças passam um tempo longo da sua infância, elas falam de si e dos seus, o que nos alimenta o interesse por saber se aí existem oportunidades de estas serem "crianças para além de alunos". (PERRENOUD, 1995, p. 32). Na senda de Perrenoud, sabemos que a escola se tem traduzido, quase exclusivamente, pelo desenvolvimento das crianças como seres aprendentes dos saberes universais socialmente tidos como fundamentais, ficando muitas vezes de fora dimensões estruturantes do seu desenvolvimento global enquanto pessoas. No entanto, efetivamente, a pessoacriança está sempre lá e são muitas as vezes que narram situações da sua vida, sejam estas mais ou menos consentidas ou até escutadas como base para planificação educativa. (SARMENTO, T. 2018, 125).

De forma aberta, numa abordagem quase naturalista, que nunca o é na totalidade porque a nossa atenção está sempre direcionada pelos objetivos de pesquisa que nos movem, procuramos nesse texto apresentar algumas reflexões a partir da observação realizada num "chão de escola": o que narram as crianças sobre as suas experiências de vida? Há momentos específicos, no decurso da rotina pedagógica, em que as narrativas acontecem? De que forma a escuta se materializa em ação educativa?

A investigação com crianças viabiliza um conhecimento aprofundado sobre suas características, suas culturas, seus modos de interação na sociedade em que está situada. Mas 
isso não se faz de um modo qualquer; investigar com as crianças pressupõe ouvi-las, dar significado às experiências que relatam e conhecer formas diversas como se exprimem.

A investigação no "chão da escola", ou meIhor dizendo, no cotidiano das práticas educativas, constitui-se como uma atividade científica e, ao mesmo tempo, como um processo de formação humana a partir do olhar sobre si mesmo e sobre o outro. A experiência de investigação pode ser comparada a uma experiência dialógica, em que as dúvidas, ideias e questionamentos ganham sentido na identificação e no confronto de ideias. Essa experiência dialógica começa muito antes do processo de escuta, inicia-se na observação e promove-se num tempo mais ou menos longo de construção de empatia e confiança, em que os saberes prévios, seja a nível pedagógico como investigativos, são andaimes necessários, mas em que, principalmente, o investigador é capaz de se abrir ao que as narrativas nos trazem de novo. Investigar e educar, formando-se com as narrativas das crianças, porque essas se exprimem de formas múltiplas e integradas - com a palavra, mas também com gestos, desenhos ou outras formas -, implica, pois, uma atitude de observação ativa,

[...] que deve ser caracterizada por escutar atentamente e mostrar disponibilidade dando espaço à criança; neste sentido, a observação nunca é neutra, mas sempre reveladora de olhares, interrogações e pontos de vista próprios de quem observa, que se cruzam com os saberes e interesses que as crianças manifestam. (MALAVASI e ZOCCATELLI, 2019, p. 10).

Ou seja, nesse sentido, procurando monitorizar continuamente a nossa forma de olhar de forma a melhor compreendermos o que as crianças querem transmitir, passamos longos períodos junto das mesmas, numa atitude de escuta capaz de acolher os sentidos que as crianças atribuem às suas narrativas.

\section{Registos cotidianos: o que}

\section{nos revelam as narrativas \\ das crianças no trabalho com projetos?}

A maior ou menor oportunidade de as crianças se narrarem na escola, revela a visão que os professores têm sobre estas, ora como meros estudantes de conteúdos académicos, ora como pessoas que têm algo a dizer sobre as suas vidas e que constroem o seu conhecimento numa interação constante entre os seus referenciais vivenciais próprios - quem sou, como sou, de onde sou, qual a minha história de vida - e os saberes entendidos como pertinentes para cada grupo de crianças, numa sociedade, tempo e espaço próprios. Em termos pessoais, e na linha de Carmen Pérez, inscrevemo-nos na linha dos que entendem que as narrativas que se desenvolvem em conversas em contexto educativo podem constituir-se

\section{[...] em dispositivos de produção de uma cultura escolar que reinventa a sala de aula a partir das redes de conversações tecidas por professoras e crianças, que colectivamente, no exercício do diálogo e na atitude da escuta, engendram mo- vimentos de desconstrução e reconstrução de saberes e práticas e possibilitam a emergência de novas experiências [...] (2014, p. 240).}

Nos jardins-de-infância, seja qual for o modelo pedagógico desenvolvido, a manhã inicia-se por uma roda de conversa em que, a exemplo da árvore das palavras ${ }^{5}$, as crianças partilham as suas narrativas e se desenvolve a socialização na relação de cada um com o seu grupo de pertença. Nesse processo, é manifesta a filtragem mais ou menos apurada que as crianças fazem de acontecimentos familiares, relatando os que the interessa por qualquer motivo. Ao longo da rotina pedagógica e nas

5 A "árvore das palavras" é uma designação africana para um espaço público tradicional em que, à sombra de uma árvore, as pessoas se juntam para conversarem e tomarem decisões comuns. 
diferentes áreas de ação existentes na sala onde jogam e brincam, dão muitas vezes continuidade a esses ou iniciam outros relatos.

Ao narrar, a criança coloca-se por inteiro naquilo que diz, seja por palavras, seja servindo-se de outras formas de expressão, evidenciando-se como "sujeito de carne e osso, feito ao mesmo tempo de razão e emoção, transpassado pela experiência e capaz de refletir sobre si mesmo". (PASSEGGI, 2016, p. 71). Passeggi realça aqui a agência da criança, a capacidade da mesma em afirmar o seu pensar e o seu sentir, afirmando-se como indivíduo. Ferrarotti (2013) defende que as pessoas estão preocupadas com os problemas que as inquietam e buscam uma ciência de mediações suscetivel de lhes trazer respostas, o que se encontra evidenciado, em muitas narrativas biográficas de crianças, em que as mesmas expressam de forma oral, escrita, pictórica ou noutro recurso, dar forma ao seu pensar e sentir, eventualmente procurando superar situações de mal-estar, de satisfação ou de desejo por algo que não existe.

Nas narrativas das suas experiências, a criança desdobra-se como espectador e como personagem, assumindo-se como ator social que sente, contesta e se posiciona, dando forma à sua condição de agente social que "age no mundo de vida, não para exercer papéis preconcebidos, mas em virtude de uma ação refletida situada no seu próprio horizonte biográfico". (PASSEGGI, 2016, p. 82) A observação de crianças em ação numa sala de jardim-de -infância facilmente nos comprova isso quando, por exemplo, na área da casa das bonecas, inicia a brincadeira dizendo "Eu era a mãe...", e nesse papel social, com um misto de passado e de condicional mas que se torna presente no momento em que brinca, (re)ativa e (re)constrói as suas experiências de interação com os outros. Ou seja, numa atividade de faz de conta, a criança biografiza-se, ativando "ope- rações mentais, comportamentais e verbais pelas quais o indivíduo não cessa de inscrever sua experiência e sua ação em esquemas temporais orientados e finalizados". (DELORYMOMBERGER, 2012, p. 525).

Valorizar os modos de participação das crianças, dando espaço a que as mesmas narrem as suas experiências de vida, pressupõe uma orientação filosófica e metodológica ancoradas numa perspectiva democrática e participativa. As pedagogias participativas colocam as crianças e adultos no centro do processo educativo, como sujeitos interativos e dialógicos. (VASCONCELOS, 2012). Os itinerários educativos são delineados a partir das narrativas das crianças; as suas indagações direcionam os processos de pesquisa a prosseguir. Nessa perspectiva, os modelos curriculares são referências importantes para a constituição da prática e identidade profissional dos educadores e criam diferentes contextos de mediação para as aprendizagens das crianças. (FOLQUE, 2018). Em especial, os modelos curriculares de base participativa aliada a uma metodologia do trabalho com projetos, que têm como ponto de partida os interesses das crianças, fomentam a construção de atitudes investigativas pela criança e pelo educador. Essas metodologias ancoram-se na construção de um currículo aberto e flexivel, guiado por um processo de indagação e reflexão. Vasconcelos (2012, p. 20) colabora com essas ideias ao afirmar que:

0 trabalho de projecto afirma uma criança investigadora, aposta na interface e na migração entre as diferentes áreas do saber e disciplinas para a resolução de um problema - a interdisciplinaridade no sentido da inter-relação dos saberes - aponta para os fins sociais da educação.

A autora chama-nos atenção para a afirmação da criança como investigadora, o que subjaz a proposição de uma escola-investigação promotora do crescimento autêntico da criança pela gestão do seu conhecimento. 
Durante a realização de um projeto, as crianças têm a possibilidade de vivenciar práticas sociais reais, pois essas partem de uma problematização da realidade, que, consequentemente, precisa ser respondida. Para Niza (2015, p. 520), "todo trabalho humano requer a idealização de um projeto" que, por sua vez, é constituído de várias etapas de trabalho que devem ser planejadas e negociadas com as crianças, para que elas possam se engajar e acompanhar o percurso até o produto final. Nesse sentido, o labor com a metodologia de trabalho de projetos parte das narrativas das crianças, do que elas trazem de experiência, de sentimentos e emoções, dando azo a ampliar ideias sobre um tema específico, tornando-as ativas na construção de um conhecimento significativo.

Vejamos a seguir algumas narrativas ${ }^{6}$ que nos ajudarão a clarificar o potencial de uma escuta sensivel e do percurso trilhado por crianças e educadora no processo de construção de uma atitude investigativa por meio de uma metodologia de trabalho com projetos:

“António (5 anos), estava a contar aos colegas como tinha corrido a sua viagem a Lisboa, onde este esteve a ver umas escavações onde se encontravam fósseis. Através desta situação, criou-se todo um diálogo em que a Educadora (atenta ao entusiasmo descritivo da criança), perguntou: - O que é um fóssil?; e o António respondeu: - É um osso de dinossauro. A Educadora voltou a perguntar: - Será que é?; ao que o Márcio (4 anos) respondeu: - Sim.

Ao ouvir isto, a Educadora disse: - Eu pen-

6 Os registos aqui inseridos são baseados nas notas da documentação pedagógica produzida pela estagiária Ana Isabel, a qual se encontrava na sala observada pelas autoras do artigo e que confirmou o consentimento informado para a utilização dessas suas descrições. O mesmo consentimento foi dado pela educadora de infância Elsa em cuja sala a observação foi feita e as notas documentam, garantindo a autorização dos responsáveis pelas crianças - pais ou encarregados de educação - para a recolha e utilização académica dos dados. sava que um osso de dinossauro era um osso de dinossauro. E o António continuou dizendo: - No nosso corpo temos ossos e os dinossauros têm fósseis. Algumas crianças diziam que isso não era verdade e chegou-se à conclusão que era necessário pesquisar o que António disse: - No nosso corpo temos ossos e os dinossauros têm fósseis, mas não sei por que se chamam fósseis.

A Educadora perguntou: - Não sabes por que se chamam fósseis? Então como vamos fazer? Sofia (6 anos) propõe: - Pesquisamos na mesa digital. Quando a Educadora sugeriu que dessem mais ideias, a Sofia retomou: - Vamos fazer um projeto para pensar nisso.

A Educadora aprova: - Acho que isso é uma ótima ideia! António não achas uma boa ideia o que a Sofia sugeriu? Fazer um projeto para se saber o que são fósseis? e ele disse: - Sim!".

Esse registro nos exemplifica os modos de participação da criança através da escuta atenta de suas experiências pela educadora e pelos seus colegas. Ao escutar a narrativa das experiências vividas pelo António num passeio com a família, a educadora, manifestando interesse pelo que ouve, questiona as ideias prévias das crianças sobre o fato narrado, procurando, a um só tempo, enfatizar a satisfação da criança narradora, dando-lhe sinais de como está satisfeita por o menino ter podido vivenciar essa experiência feliz, rentabilizando educativamente a mesma, expandindo-a para as outras crianças. A atitude atenta e sensivel leva à construção de um processo de investigação que terá como problemática/ponto de partida: o que são fósseis?

Ainda nesse relato, é interessante observar o espaço de escuta coletiva delimitado na rotina e a percepção que algumas crianças apresentam acerca do trabalho com projetos, o que demonstra que essa metodologia de trabalho é algo constante na turma, e que as mesmas já têm clareza sobre que caminhos podem per- 
correr para responder às suas dúvidas e curiosidades, favorecendo, assim, a construção de atitudes investigativas pelas mesmas.

É importante esclarecer que a educadora organiza sua prática pedagógica a partir dos princípios do modelo curricular do MEM, o qual, de acordo com o fundador Sérgio Niza, "[...] assenta num Projeto democrático de autoformação cooperada de docentes, que transfere, por analogia, essa estrutura de procedimentos para um modelo de cooperação educativa nas escolas." (NIZA, 2013, p. 142), processo designado por isomorfismo pedagógico.

Como pressupostos do processo educativo nos jardins de infância de orientação do MEM, temos: a constituição dos grupos de crianças com diferentes idades, de modo a assegurar a "heterogeneidade geracional e cultural" (NIZA, 2013, p. 149), garantindo assim o respeito pelas diferenças individuais e o desenvolvimento de ajuda cooperada entre os pares. A livre expressão da criança é, assim, estimulada, de modo sensível, pelo educador e por seus pares, nos momentos coletivos de partitha e planificação. O tempo lúdico de "atividade exploratória das ideias, dos materiais ou dos documentos para que possa ocorrer a interrogação que suscite projetos de pesquisa, auto-propostos ou provocados pelo educador [...]" (NIZA, 2013, p. 149)

Todos esses elementos resultam no diálogo que registramos ao longo desse texto, ou seja, na interação de crianças de diferentes idades, que estimulada pela educadora, acolhe na planificação cotidiana de sua prática, as crianças com sua cultura, saberes, ideias e vivências, resultando em uma democracia participada e na gestão cooperada do currículo.

Nesta sala, a interação entre crianças e adultos acontece muito naturalmente, pelo que as crianças partilham regularmente as suas emoções, as suas ideias e propósitos, como se pode perceber no registo seguinte:
"A Mafalda e o António inscreveram-se no 'Contar, mostrar e escrever', sendo que a Mafalda acabou por não contar nada. Já o António começou por dizer: - Tenho aqui uma coisa que a minha tia me mandou. A Educadora perguntou: - Quem é a tua tia? o que faz? Tens que dizer quem é porque os meninos novos, a Ana, a Sílvia e a Mãe do Manuel não sabem; e o menino respondeu: - A minha tia chama-se Isabel [...] Tia da Selva. Para continuar a conversa a Educadora questionou a criança: - Onde é que ela está?, ao que o menino respondeu: - Em África. A conversa foi fluindo e a Educadora perguntou: - O que é que ela está lá a fazer?, e o António declarou: - Está a ajudar os meninos; para clarificar esta questão a Educadora disse: - Está a fazer uma coisa que nós também fazemos. Vo...; e ele e a Sofia responderam: Voluntariado. A Educadora afirmou: - Ser voluntário é trabalhar sem ganhar dinheiro. De seguida o António contou: - Veio a colega de lá e trouxe-me isto; mostrando um saco com uma carta para o jardim de infância e um saco de mancarras (típico da zona). Ao ver isso a Educadora questionou: - Por que é que ela tem um carinho muito especial por nós?; ao que a Sofia respondeu: - Porque nós fizemos um projeto para ajudar crianças. Após se falar no projeto o António comentou: - Eles são muito inteligentes, fizeram girafas com lixo. No final a Educadora leu a carta da Tia que Vive na Selva dirigida às crianças do jardim de infância, em que esta dizia que as crianças que ficaram com os equipamentos chegaram às meias finais".

$\mathrm{Na}$ análise dessa nota de campo, a Ana Isabel refere que no ano anterior essas crianças tinham já desenvolvido um projeto com base nas constantes estórias que o António trazia para a sala, escritas pela tia que vive na selva,

7 O "Contar, mostrar e escrever" consiste numa componente do modelo pedagógico MEM, que consiste num tempo da rotina pedagógica em que as crianças, de forma organizada, porque a vivência em sociedade assim o requer, socializam com todo o grupo - crianças e educadora - experiências significativas. 
a qual encontrou na escrita de cartas sobre situações vivenciadas por si em países africanos o meio para reforçar a ligação afetiva entre tia e sobrinho. Atenta e valorizadora das narrativas (auto)biográficas das crianças, a educadora, a partir da exploração do significado de se ser voluntário, e vendo aí uma janela para as crianças acederem a outros mundos, mediou um projeto que possibilitou múltiplas aprendizagens sobre multiculturalidade, diversidade biológica, geográfica e cultural. Entre outras atividades, esse projeto mobilizou as famílias e um clube de futebol nacional no sentido de, em colaboração com as crianças, arranjarem equipamentos desportivos para que outros meninos pudessem concretizar também alguns dos seus sonhos, no caso, o de se apresentarem como uma equipa de futebol com que se identificavam.

A interpretação desses registos nos leva a refletir a importância da interação entre os sujeitos. Fundamentadas nas concepções de Vygotsky (1988), compreendemos que todo o processo formativo envolve a apropriação de conhecimentos e de práticas culturais pertencentes a cada sujeito situado em seu contexto histórico e cultural. Esse processo é denominado de internalização, ou seja, é a conversão dos processos sociais em processos individuais que não se faz de modo direto e imediato, mas mediados pela intervenção do outro e da linguagem, enquanto significações.

É nessa interação propiciada pelo contato diário entre a educadora e as crianças que reside um processo formativo, numa prática pautada em práticas de cooperação e de solidariedade de uma vida democrática. (NIZA, 2013). Nessas situações concretas - que sintetizam muitas outras observadas em que a voz das crianças e as suas tomadas de decisão estão presentes em processos partilhados entre si e com a educadora -, os seus modos próprios de contar suas experiências e vivências nos mais diversos contextos, instigam à reflexão do grupo de crianças e da própria educadora. Para Sofia, no último registo, a memória do projeto solidário continua a ser empolgante, para António, o conhecimento que os relatos da tia the proporcionam aquecem o afeto que nutre pela mesma, para a educadora, essa situação foi mais uma oportunidade de observar o modo como as crianças se revelam emocional, social e cognitivamente, o que a ajuda a, com elas, definir os caminhos educativos a trilhar.

Esses registos comprovam que as crianças têm uma margem de participação significativa na produção dos dados e nas oportunidades de interpretação que os mesmos possibilitam, na medida em que nas suas narrativas não fazem cópias lineares do mundo dos adultos; elas apropriam-se e ressignificam esse mundo. (PEÑA, 2014, p. 176). Larrosa afirma que as crianças, ao mesmo tempo que se apropriam da cultura, interferem culturalmente, a partir dos significados que atribuem às situações, agindo no sentido da transformação das mesmas, formulando conhecimentos próprios e produzindo culturas próprias e únicas; ou seja, as crianças são "agentes competentes" (CORSARO, 2003), que vivem em mundos sociais em que não são neutras e meras recetoras; o seu eu está em constante desenvolvimento entre o seu interior, as condições externas com que se entrelaça, em tempos e em espaços demarcados. Nessa perspetiva, como lembra Furlanetto (2014, p. 164),

[...] tornam-se necessárias revisões nas teorias a respeito dos processos de socialização: se por um lado as crianças são estimuladas a se apropriarem de elementos culturais e dessa forma a se assemelharem entre si, por outro, ao viverem esses processos não internalizam simplesmente os padrões oferecidos pelos adultos, mas os interpretam, o que implica viver, simultaneamente, processos de socialização e de singularização. 
Digamos, então, que essa forma de trabalho de investigação com crianças protagoniza - as como atores sociais com autoria na produção das suas narrativas, do sentido que atribuem às mesmas e na influência que podem exercer nos seus grupos de pertença; logo, são sujeitos, encontram aqui um espaço relevante na sua afirmação social e no seu poder político. (FOLQUE, 2010).

\section{Narrativas de crianças e ação educativa}

Com base nos nossos pressupostos teóricos e na observação e análise produzida, sistematizamos agora a reflexão produzida, orientada pelos três cenários previamente definidos.

1) As narrativas das crianças como reconhecimento do direito a serem ouvidas e respeitadas em seus interesses, necessidades e modos próprios de participação:

Do nosso questionamento partilhado com outros investigadores e com professores de crianças pequenas, da observação realizada e da análise conceptual sequente, saímos reforçadas no posicionamento de que a participação das crianças nos processos que lhes digam respeito, no sentido de "nada para a criança sem a criança" (PASSEGGI, 2014, p. 133), é um direito que afirmamos, assumindo a sua autoria social e (co)autoria investigativa.

As crianças, enquanto pessoas com agência própria, têm direito a serem ouvidas nos seus anseios, interesses e opiniões. A forma como se expressam é múltipla, sendo as narrativas orais um recurso que as mesmas cotidianamente utilizam... é preciso que educadores estejam atentos a escutá-las e a reconhecer-lhes o sentido. Percebemos que essa é uma realidade muito presente no cotidiano educativo, sendo que nos jardins-de-infância existem vários momentos da rotina pedagógica em que tal acontece, ora de forma espontânea, ora mesmo induzido pelos profissionais. Verificamos também que as crianças colocam grande entusiasmo quando se narram, fazendo-o integralmente, ou seja, com palavras, com emoção, com expressões corporais, revelando-se e reencontrando-se nas ligações afetivas com os seus e com os conhecimentos que, suportados nessas ligações afetivas, vão construindo.

Cada criança está "exposta a múltiplas vozes, múltiplas perspetivas" (LEAL da COSTA e SARMENTO, T. 2018, 75), pelo que a sua narrativa (auto)biográfica decorre dessa interação entre si e os outros, em que cada uma não é mais um sujeito individual finito em si mesmo, mas um ser social que de forma singular expressa a sua experiência de vida, andaimando a sua identidade como cidadã.

2) As narrativas (auto)biográficas das crianças como princípio básico na planificação e organização da ação educativa:

Para as crianças, a investigação através de projetos é uma potencial ferramenta de descoberta e motivação. É uma metodologia flexível, partilhada na interação com os colegas e a educadora. Uma porta aberta para a construção do exercício de ser cidadã, de poder participar ativamente do seu próprio processo de aprendizagem, partindo da compreensão da realidade social em que está inserida, intervindo e transformando a mesma.

O trabalho com a metodologia de projetos possibilita o desenvolvimento de uma atitude investigativa, podendo ser definida como uma atividade intencional e social, que contempla uma pesquisa a ser planeada e desenvolvida por meio da cooperação e responsabilidade mútua, bem como estimula a autonomia e a iniciativa da criança por meio de atividades e experiências diversificadas.

0 que os professores fazem com essas narrativas (auto)biográficas difere de caso para caso, consoante a visão que cada um tem sobre a criança enquanto tal ou no seu papel de 
aluno, e sobre a forma como organizam e gerem a sua ação pedagógica. Desenvolver a ação educativa a partir das narrativas das crianças é a manifestação do respeito pela sua voz e pelos seus próprios processos de construção de conhecimento.

A promoção de uma cultura de observação e de uma escuta sensivel às manifestações das crianças, discutida amplamente no campo teórico, merece ser concretizada e ampliada no plano da prática pedagógica. Ousamos insistir nos estudos acerca da importância das narrativas das crianças como uma necessidade inerente à ação educativa. É urgente tecer as práticas com o fio condutor da participação ativa de todos os sujeitos envolvidos no processo: crianças e educadores.

3) (Re)pensar a formação de professores partindo da ideia de que a investigação no cotidiano das práticas permite o desenvolvimento da capacidade investigativa e reflexiva de crianças e adultos.

As interações com as crianças e seus familiares configuram-se como um importante processo de formação porque a construção de conhecimentos, saberes e fazeres do educador estão intrinsecamente ligados à prática profissional que é também contingenciada pela dinâmica cotidiana. Portanto, suas formas de ação, de atuação na prática pedagógica estão carregadas, entrelaçadas por saberes construídos, refletidos e tomados para si em diversos momentos do dia a dia, em sua trajetória de vida e em múltiplos espaços de atuação e de interação com outros, em especial, com as crianças.

0 entendimento do professor como investigador, no sentido da produção ao serviço da melhoria das práticas, tem vindo a ser abordado por diferentes autores e a ser implementado por muitos profissionais do chão da escola. Naturalmente, que a mudança de um paradigma em que o professor era um executante de saberes produzidos por acadêmicos para um novo paradigma em que os profissionais são coautores desses conhecimentos é um passo em frente no compromisso social que a educação exige. É na interação dos professores com as crianças e com as comunidades que se fazem as principais aprendizagens não técnicas, mas fundamentais, da profissão. É no contato com situações reais, com crianças não padronizadas, com a diversidade de populações, que os professores aprendem outra forma de ver o mundo, o que os obriga a racionalizar emotivamente sobre a ação de professor: alguém que ensina, que transmite, mas, sobretudo, que tem que aprender como tornar significativos os saberes com as crianças e consigo próprio, com vista à finalidade última da educação, que é promover cada um enquanto pessoa.

\section{Referências}

BARBIER, René. Escuta sensivel na formação de profissionais de saúde. Conferência na Escola Superior de Ciências da Saúde - FEPECS - SES-GDF, Brasília, julho de 2002. Disponivel em: http://www.barbier -rd.nom.fr/ESCUTASENSIVEL.PDF. Acesso em: 10 mar. 2020.

BARBOSA, Maria Carmem Silveira; HORN, Maria da Graça Souza. Projetos pedagógicos na educação infantil. Porto Alegre: Artmed, 2008.

CORSARO, William A. We're friends, right?: inside kids' cultures. Washington, dc: Joseph Henry Press, 2003.

COSTA, Conceição Leal e SARMENTO, Teresa. Escutar as crianças e (re) configurar identidades - interações com voz. Educação e Análise, Londrina, v.3, no. 2, p. 72-94, 2018. Disponivel em: http://www. uel.br/revistas/uel/index.php/educanalise/article/ view/33684. Acesso em: 10 jan. 2020.

DALHLBERG, Gunilla; MOSS, Peter; PENCE, Alan. Qualidade na educação da primeira infância: perspectivas pós-modernas. Porto Alegre: Artmed. 2003.

DELORY-MOMBERGER, Christine. Abordagens meto- 
dológicas na pesquisa biográfica. Revista Brasileira de Educação, Rio de Janeiro, v. 17, no - 51, p. 523-536. 2012. Disponivel em: https://www.scielo.br/pdf/ rbedu/v17n51/02.pdf. Acesso em: 10 mar. 2020.

FERNANDES, Natália. Ética na pesquisa com crianças: ausências e desafios. Revista Brasileira de Educação, Rio de Janeiro, v. 21, n. 66, p. 759-779, set. 2016. Disponivel em: http://www.scielo.br/scielo. php. Acesso em: 10 jan. 2020.

FERRAROTTI, Franco. Sobre a ciência da incerteza: o método biográfico na investigação em Ciências Sociais. Mangualde: Ed. PEDAGO.

FOLQUE, Assunção. $\mathbf{O}$ aprender a aprender no pré -escolar: o modelo pedagógico do Movimento da Escola Moderna. 3. ed. Lisboa: Fundação Calouste Gulbenkian. 2018.

FOLQUE, Assunção. Interviewing Young Children. In: MAC NAUGHTON, Glenda; NAUGHTON, Rolfe e SirajBlatch, Iram (Orgs). Doing early childhood research. Australia: Allen \& Unwin. 2010. p. 239-260.

FORMOSINHO, João. Prefácio. In: OLIVEIRA-FORMOSINHO, Júlia. (org.) Modelos curriculares para a educação de infância: construindo uma práxis de participação. 3.ed. Porto: Editora Porto, 2013. p. 9-24.

KRAMER, Sonia. Autoria e autorização: questões éticas na pesquisa com crianças. Cadernos de Pesquisa, São Paulo, n.116, p. 41-49, jul., 2002. Disponivel em: https://www.scielo.br/scielo.php?pi$d=$ S0100 $-15742002000200003 \&$ script=sci_abstrac t\&tlng=pt. Acesso em: 10 jan. 2020.

KRAMER, Sonia. Profissionais de educação infantil: gestão e formação. São Paulo: Ática, 2005.

LARROSA, Jorge. Pedagogia Profana: danças, piruetas e mascaradas. 4a edição. Belo Horizonte: Autêntica. 2006.

LOPES, Denise Maria de Carvalho. Falar e ser ouvido verdadeiramente. Revista letra A. v. 12, n. 47, p. 1315, 2016. Disponivel em: http://www.ceale.fae.ufmg. $\mathrm{br} /$ pages/view/falar-e-ser-ouvido-verdadeiramente-2.html. Acesso em: 10 jan. 2020.

MALAVASI, Laura; ZOCCATELLI, Barbara. Documentar os projetos nos serviços educativos. 4. ed. Lisboa:
APEI - Associação de profissionais de educação de infância. 2019.

MOITA, Maria da Conceição. Percursos de formação e de trans-formação. In: NÓVOA, António. Vida de professores. 2. ed. Porto: Editora Porto. 2007. p. 111140.

NIZA, Sérgio. Escritos sobre educação. 2. Ed. Lisboa: Tinta da china. 2015.

NIZA, Sérgio. O Modelo Curricular de Educação Pré -escolar da Escola Moderna Portuguesa. In: OLIVEIRA-FORMOSINHO, Júlia. (org.). Modelos curriculares para a educação de infância: construindo uma práxis de participação. 3.ed. Porto: Editora Porto. 2013. p. $141-160$.

PASSEGGI, Maria da Conceição. Nada para a criança, sem a criança: o reconhecimento de sua palavra para a pesquisa (auto)biográfica. In: MIGNOT, Ana Chrystina; SAMPAIO, Carmen Sanches e PASSEGGI, Maria da Conceição (Orgs). Infância, aprendizagem e exercício da escrita. Curitiba: Editora CRV, 2014. p. 133-147.

PASSEGGI, Maria da Conceição; NASCIMENTO, Gilcilene; OLIVEIRA, Roberta. As narrativas autobiográficas como fonte e método de pesquisa qualitativa em Educação. Revista Lusófona de Educação. Lisboa, v. 33, n. 33, p. 111-125, 2016. Disponivel em: https:// revistas.ulusofona.pt/index.php/rleducacao/issue/ view/688. Acesso em: 10 jan. 2020.

PASSEGGI, Maria da Conceição. Narrativas da experiência na pesquisa formação: do sujeito epistêmico ao sujeito biográfico. Roteiro. Joaçaba, v. 41, n. 1, p. 67-86, 2016. Disponivel em: https://www.researchgate.net/publication/299403604. Acesso em: 10 jan. 2020.

PEÑA, Andrés. Los espácios pre-escolares vivenciados y narrados por niños y niñas: estudios sobre la formación de la infância desde un enfoque denomenológico-narrativo. In: MIGNOT, Ana Chrystina; SAMPAIO, Carmen Sanches e PASSEGGI, Maria da Conceição (Orgs). Infância, aprendizagem e exercício da escrita. Curitiba: Editora CRV, 2014. p. 173-192.

PÉREZ, Carmen. De criança para criança: a produção da revista electrónica "Tô de olho" como afirma- 
ção da autoria. In: MIGNOT, Ana Chrystina; SAMPAIO, Carmen Sanches e PASSEGGI, Maria da Conceição (Orgs). Infância, aprendizagem e exercício da escrita. Curitiba: Editora CRV, 2014. p. 235-248.

PERRENOUD, Philippe. Oficio de aluno e sentido do trabalho escolar. Porto: Porto Editora. 1995

RICOEUR, Paul. Tempo e Narrativa I. Campinas: Papirus, 1994.

SARMENTO, Teresa. Narrativas (auto)biográficas de crianças: alguns pontos em análise. In: PASSEGI, Maria da Conceição [et.al.] (Orgs). Pesquisa (auto) biográfica em educação infâncias e adolescências em espaços escolares e não escolares. Natal: Edufrn, 2018. p. 121-141.

VASCONCELOS, Teresa. Trabalho por projetos na educação de infância: mapear aprendizagens/integrar metodologias. Lisboa: Direção-Geral da Educação (DGE), 2012. 144p.

VYGOTSKY, Lev. A formação social da mente. 6. ed. São Paulo: Martins Fontes, 1988.

Recebido em: 06/04/2020 Aprovado em: 16/08/2020

Teresa Sarmento é professora auxiliar no Instituto de Educação, Universidade do Minho, pertencente ao Departamento de Ciências Sociais da Educação e ao Centro de Investigação em Estudos da Criança. Docente e investigadora da área de formação de professores e educação de infância, é especialista em pesquisa (auto)biográfica nessas áreas, com estudos publicados em múltiplas revistas científicas e livros, a nível nacional e estrangeiro. E-mail: tsarmento@ie.uminho.pt

Milena Oliveira é docente da Universidade Federal Rural do Semi-Árido (Ufersa), em Mossoró, possui o mestrado em Educação e encontra-se atualmente a desenvolver o doutoramento na linha de pesquisa Educação, currículo e práticas pedagógicas, tendo realizado um estágio científico avançado no Instituto de Educação, Universidade do Minho. E-mail: milenapaulac@yahoo.com.br 